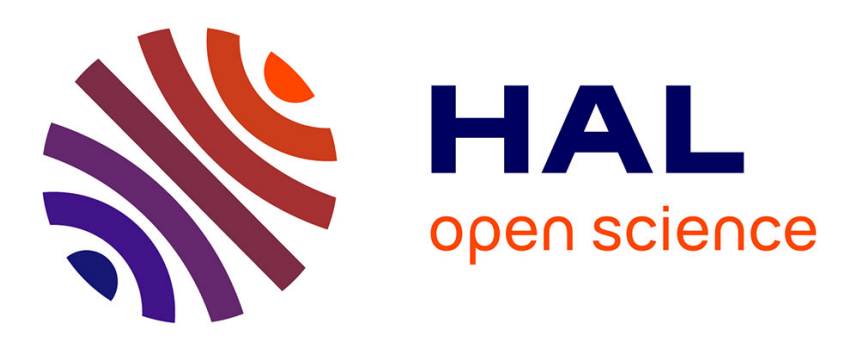

\title{
Correlation between prosody and pragmatics: case study of discourse markers in French and English
}

Lou Lee, Denis Jouvet, Katarina Bartkova, Yvon Keromnes, Mathilde Dargnat

\section{To cite this version:}

Lou Lee, Denis Jouvet, Katarina Bartkova, Yvon Keromnes, Mathilde Dargnat. Correlation between prosody and pragmatics: case study of discourse markers in French and English. INTERSPEECH 2020, Oct 2020, Shanghai, China. hal-02968475

\section{HAL Id: hal-02968475 \\ https://hal.inria.fr/hal-02968475}

Submitted on 15 Oct 2020

HAL is a multi-disciplinary open access archive for the deposit and dissemination of scientific research documents, whether they are published or not. The documents may come from teaching and research institutions in France or abroad, or from public or private research centers.
L'archive ouverte pluridisciplinaire HAL, est destinée au dépôt et à la diffusion de documents scientifiques de niveau recherche, publiés ou non, émanant des établissements d'enseignement et de recherche français ou étrangers, des laboratoires publics ou privés. 


\title{
Correlation between prosody and pragmatics: case study of discourse markers in French and English
}

\author{
Lou Lee $^{1,2}$, Denis Jouvet ${ }^{2}$, Katarina Bartkova ${ }^{1}$, Yvon Keromnes ${ }^{1}$, Mathilde Dargnat ${ }^{1}$ \\ ${ }^{1}$ Université de Lorraine, CNRS, ATILF, F-54000 Nancy, France \\ ${ }^{2}$ Université de Lorraine, CNRS, Inria, LORIA, F-54000 Nancy, France \\ \{lou. lee; katarina.bartkova; yvon. keromnes; mathilde.dargnat\}@univ-lorraine.fr, \\ denis.jouvetaloria.fr
}

\begin{abstract}
This paper investigates the prosodic characteristics of French and English discourse markers according to their pragmatic meaning in context. The study focusses on three French discourse markers (alors ['so'], bon ['well'], and donc ['so']) and three English markers (now, so, and well). Hundreds of occurrences of discourse markers were automatically extracted from French and English speech corpora and manually annotated with pragmatic functions labels. The paper compares the prosodic characteristics of discourse markers in different speech styles and in two languages. The first comparison is carried out with respect to two different speech styles in French: spontaneous speech vs. prepared speech. The other comparison of the prosodic characteristics is conducted between two languages, French vs. English, on the prepared speech. Results show that some pragmatic functions of discourse markers bring about specific prosodic behaviour in terms of presence and position of pauses, and their F0 articulation in their immediate context. Moreover, similar pragmatic functions frequently share similar prosodic characteristics, even across languages.
\end{abstract}

Index Terms: prosody, pragmatics, discourse markers, F0 patterns

\section{Introduction}

Discourse markers are words that are used on a discursive or situational level instead of a referential or textual level. They convey a different pragmatic meaning depending on the context or discourse situation. There have been a great number of empirical studies wholly dedicated to this semantico-pragmatic phenomenon for the past decades (e.g., [1], [2], [3]). In order to understand them accurately, it is essential to study their pragmatic functions, that is the communicative goal they serve in discourse situations.

Some authors have studied different pragmatic functions of discourse markers and the ambiguity in their meanings as well as their disambiguation [4]. The multifunctionality and ambiguity of discourse markers often stem from their dependency on the context to define their meaning [5], [6]. In fact, not only discourse markers can have an almost infinite number of functions depending on context, but also different markers can share some of their meanings [7].

Prosody is frequently used in research on discourse or emotional speech due to the fact that it expresses a meaning going beyond the traditional semantic meaning [8], [9], [10]. However, the prosody of discourse markers has been relatively little studied, especially for the French language. Prosody can convey very important and useful information allowing to detect discursive and pragmatic meanings of these markers.

A few recent studies have found correlation between prosodic parameters of discourse markers and their usage [11], [12], [13]. According to these studies, prosodic information predicts successfully whether the word is used as a marker or a non-marker. For instance, discourse markers are often phonetically reduced or unstressed compared to the 'standard' usage of the same word not as a marker [14]. In addition, prosody can predict more specific pragmatic meanings of the marker in context. There are also a number of case studies on a specific discourse marker, on how prosody reflects this semantico-pragmatic change in a word [15], [16], [17].

In this study, we present a prosodic analysis of three French discourse markers (alors ['so', 'then', 'well'], bon ['well', 'right'], and donc ['so', 'then']) and three English markers (now, so, and well) according to their different pragmatic functions. As we observed in our previous studies on French discourse markers [18], [19], [20], [21], prosodic production of discourse markers depends on their pragmatic function in the context. The present study is focussed on a comparison between prosodic correlates of discourse markers with respect to pragmatic functions, firstly in different speech styles and secondly across different languages. The first comparison is conducted on French speech data between spontaneous and prepared speech. Then another comparison is conducted on prepared speech between French and English data.

The paper is organised as follows. Section 2 presents the speech corpus, the annotation of the data and the prosodic features used. Section 3 compares the prosodic characteristics of the words under consideration between two speech styles (prepared vs. spontaneous) on the French data. Section 4 presents a comparison between French and English data on prepared speech, followed by the conclusion of the study.

\section{Speech corpora and annotations}

\subsection{French and English corpora}

Occurrences of the words studied, frequently used as discourse markers, were randomly extracted from French and English corpora. The French corpora cover various speech styles of different levels of spontaneity: ESTER2 [23], a corpus of radio broadcast news composed of prepared speech by journalists and some interviews, and the corpora of the project ORFEO [22] composed of a large variety of speech from storytelling to interviews and daily dialogues. They amount for several hundreds of hours of speech data. For English, the corpus TED-LIUM 3 
Table 1: Number of occurrences of discourse markers, and percentage of associated pragmatic function

\begin{tabular}{|c|c|c|c|c|c|c|c|c|c|}
\hline \multirow[b]{2}{*}{ Pragmatic function } & \multicolumn{3}{|c|}{ French-spontaneous } & \multicolumn{3}{|c|}{ French-prepared } & \multicolumn{3}{|c|}{ English-prepared } \\
\hline & alors & bon & donc & alors & bon & donc & now & so & well \\
\hline Number of items & 668 & 570 & 618 & 125 & 106 & 161 & 76 & 109 & 108 \\
\hline Introduction & $12 \%$ & $6 \%$ & $6 \%$ & $34 \%$ & $20 \%$ & $10 \%$ & $33 \%$ & $12 \%$ & $6 \%$ \\
\hline Resuming & $15 \%$ & & $22 \%$ & $3 \%$ & & $20 \%$ & $13 \%$ & $27 \%$ & $9 \%$ \\
\hline Conclusion & $14 \%$ & $4 \%$ & $23 \%$ & $8 \%$ & $0 \%$ & $21 \%$ & & $39 \%$ & \\
\hline Hesitation & $6 \%$ & $7 \%$ & $9 \%$ & $4 \%$ & $8 \%$ & $3 \%$ & & & \\
\hline Parenthesis & $15 \%$ & $17 \%$ & $18 \%$ & $32 \%$ & $26 \%$ & $31 \%$ & $54 \%$ & $21 \%$ & $24 \%$ \\
\hline Reformulation & $3 \%$ & $8 \%$ & $4 \%$ & $2 \%$ & $9 \%$ & $7 \%$ & & & $5 \%$ \\
\hline Confirmation & & $10 \%$ & & & $17 \%$ & & & & \\
\hline Closing & & $6 \%$ & & & $8 \%$ & & & & \\
\hline Quotation & & & & & & & & $1 \%$ & $23 \%$ \\
\hline Self-response & & & & & & & & & $26 \%$ \\
\hline Turn-taking & $11 \%$ & & & $10 \%$ & & & & & $6 \%$ \\
\hline
\end{tabular}

[24] was used. It is composed of 452 hours of speech, recordings of TED Talks. Manual transcriptions of these corpora were automatically aligned with the speech signal allowing us to locate the positions of the words.

As already stated, the words under study are: alors, bon, donc for French, and now, so, well for English. These words, often used as discourse markers, were chosen because they are frequent in our corpora, and thus we can expect to have enough data for a relevant and reliable analysis. For French, 500 to 1,000 occurrences were randomly extracted for each word studied, with a context of 15 words before and 15 words after so that it is possible to understand the meaning and function of the word in its context. Each word occurrence was annotated manually with labels indicating its usage: discourse marker (DM) or not (non-DM). The annotation was further refined for the discourse markers to determine their pragmatic functions. For most of the words, approximately $70 \%$ of their occurrences were identified as discourse markers. The same process was conducted for the English data, but only 200 occurrences were extracted for each word studied. The phonemic segmentation of the words of interest (i.e., the word under study, and its immediate left and right context) was manually verified and corrected where necessary.

\subsection{Pragmatic functions of discourse markers}

The semantic load of a word when used as a discourse marker is significantly lighter compared to the one when used as a nonmarker [1], [25]. A discourse marker conveys mainly pragmatic meanings in the discourse. Besides, more than one pragmatic meaning can be attributed to a discourse marker, depending on its context.

For each word under study, pragmatic function labels were chosen first according to the literature [26], [27], [28], [29], then were adjusted during the process of annotation to cover other pragmatic functions observed in our own speech data. Each discourse marker under study has from three up to seven different pragmatic functions, and these functions can be shared among different discourse markers (cf. [21] for more information on the annotation process). Table 1 shows the number of occurrences that are used as discourse markers, and the frequency of each pragmatic function for each discourse marker. The table excludes infrequent labels and complex discourse marker usages (when more than one marker is used in combination, for instance "enfin bon"), which explains why the sum of the percentages in the table does not reach $100 \%$. This is particularly the case for "bon" which is frequently used with other markers, probably due to its monosyllabicity.
In the remainder of the paper, we will limit the analysis to pragmatic functions that are shared by several discourse markers and appear frequently in both languages. The following are the pragmatic functions considered in this study, with associated examples (\{transcription, where ' + ' indicates the presence of a pause\}, "file ID", and [time interval]):

- Introduction (to introduce a new topic or start talking): that's what color printers do i'll show you in a moment that's actually quite useful ++ now the next question that you would like to ask is what would you like to 3 "GeorgeWhitesides_2009X" [386.955-395.960]

- Conclusion (to introduce a conclusion): \{since been found in countless other + experiments around the globe from the us + to india $+++\underline{\mathbf{s} 0}+$ here's what i've learned ++ when it comes to poverty + we + the rich + should stop $\}$ "RutgerBregman_2017" [573.910-591.840]

- Parenthesis (to add a comment or an extra information): \{like ok let's look at television so they looked at an episode of lost now i don't have a tv which makes me a freak but very\} "Jenny8Lee_2008P" [744.995-749.985]

- Resuming (to continue a topic after a detour or a pause): $\{i$ i've not yet done anything + to make any human being remember that $i$ have lived $++\underline{\text { so }}$ fueled by that ambition he returned to the state legislature he eventually won a\} "DorisKearnsGoodwin_2008" [216.735-226.345]

\subsection{Prosodic parameters in question}

In the following we will analyse the presence of pauses before or after the discourse markers, as well as the evolution of the fundamental frequency.

The presence of pauses before and/or after the discourse markers is determined from the phonetic alignments, that were obtained automatically, checked manually and corrected when necessary, with respect to the studied discourse markers and their immediate left and right contexts.

The fundamental frequency values (F0) have been computed using the RAPT algorithm [30] from the SPTK toolkit [31], which provides good F0 estimates in many conditions [32]. The F0 values have been converted into semi-tones, in comparison to the median F0 value of each speaker [33]. This allows a better interpretation of the F0 values with respect to the speaker's theoretical vocal range, which extends from the median F0 value minus 6 semi-tones (half an octave below) to the median value plus 6 or 12 semi-tones (half an octave or an octave above). We analysed the F0 movements between the words under consideration and the stressed or potentially stressed vowels of their immediate contexts (i.e., previous and 
Table 2: Number of occurrences of discourse markers and percentage of position of pause(s) in the immediate context

\begin{tabular}{|c|c|c|c|c|c|c|c|c|c|c|}
\hline \multirow[b]{2}{*}{ Pragmatic function } & \multirow[b]{2}{*}{ Position of pause(s) } & \multicolumn{3}{|c|}{ French-spontaneous } & \multicolumn{3}{|c|}{ French-prepared } & \multicolumn{3}{|c|}{ English-prepared } \\
\hline & & alors & bon & donc & alors & bon & donc & now & so & well \\
\hline \multirow{4}{*}{$\begin{array}{l}\text { None } \\
\text { (Non-DM usage) }\end{array}$} & No. of items & 78 & 92 & 19 & 57 & 72 & 18 & 98 & 54 & 67 \\
\hline & none & $58 \%$ & $68 \%$ & $53 \%$ & $46 \%$ & $75 \%$ & $67 \%$ & $59 \%$ & $78 \%$ & $70 \%$ \\
\hline & before only & $37 \%$ & $5 \%$ & $21 \%$ & $37 \%$ & $6 \%$ & $6 \%$ & $8 \%$ & $15 \%$ & $3 \%$ \\
\hline & before and after & $0 \%$ & $0 \%$ & $0 \%$ & $9 \%$ & $4 \%$ & $17 \%$ & $2 \%$ & $0 \%$ & $0 \%$ \\
\hline \multirow{4}{*}{ Introduction } & No. of items & 69 & 33 & 32 & 42 & 21 & 16 & 25 & 13 & 7 \\
\hline & none & $13 \%$ & $30 \%$ & $41 \%$ & $10 \%$ & $29 \%$ & $94 \%$ & $12 \%$ & $15 \%$ & $43 \%$ \\
\hline & before only & $57 \%$ & $48 \%$ & $56 \%$ & $69 \%$ & $67 \%$ & $6 \%$ & $52 \%$ & $46 \%$ & $57 \%$ \\
\hline & before and after & $29 \%$ & $6 \%$ & $3 \%$ & $19 \%$ & $5 \%$ & $0 \%$ & $32 \%$ & $31 \%$ & $0 \%$ \\
\hline \multirow{4}{*}{ Resuming } & No. of items & 100 & & 136 & 4 & & 32 & 10 & 28 & 10 \\
\hline & none & $12 \%$ & & $29 \%$ & $0 \%$ & & $31 \%$ & $0 \%$ & $4 \%$ & $0 \%$ \\
\hline & before only & $73 \%$ & & $65 \%$ & $75 \%$ & & $53 \%$ & $70 \%$ & $61 \%$ & $60 \%$ \\
\hline & before and after & $13 \%$ & & $5 \%$ & $25 \%$ & & $12 \%$ & $30 \%$ & $32 \%$ & $40 \%$ \\
\hline \multirow{4}{*}{ Conclusion } & No. of items & 92 & 20 & 139 & 10 & 0 & 33 & & 41 & \\
\hline & none & $34 \%$ & $10 \%$ & $42 \%$ & $30 \%$ & $0 \%$ & $55 \%$ & & $24 \%$ & \\
\hline & before only & $36 \%$ & $50 \%$ & $50 \%$ & $50 \%$ & $0 \%$ & $39 \%$ & & $61 \%$ & \\
\hline & before and after & $10 \%$ & $40 \%$ & $4 \%$ & $20 \%$ & $0 \%$ & $0 \%$ & & $12 \%$ & \\
\hline \multirow{4}{*}{ Parenthesis } & No. of items & 101 & 97 & 110 & 40 & 28 & 50 & 41 & 23 & 26 \\
\hline & none & $36 \%$ & $54 \%$ & $57 \%$ & $42 \%$ & $39 \%$ & $84 \%$ & $20 \%$ & $43 \%$ & $15 \%$ \\
\hline & before only & $54 \%$ & $36 \%$ & $38 \%$ & $40 \%$ & $32 \%$ & $8 \%$ & $54 \%$ & $48 \%$ & $62 \%$ \\
\hline & before and after & $8 \%$ & $8 \%$ & $2 \%$ & $10 \%$ & $21 \%$ & $0 \%$ & $24 \%$ & $4 \%$ & $15 \%$ \\
\hline
\end{tabular}

following words). In French, we have considered the F0 value on the last (potentially stressed) vowel of the left context (w-1), on the last (potentially stressed) vowel of the word under consideration, and on the last (potentially stressed) vowel of the following word $(w+1)$. In English, we have considered the F0 values on the stressed vowel of the left context (w-1), on the vowel of the word under consideration (all the English markers studied are monosyllabic), and on the stressed vowel of the following word $\left(\mathrm{w}^{+}+1\right)$. A vector quantisation procedure was then applied to all the data to extract representative patterns of F0 movements. Furthermore, patterns of difference in value of under 3 semi-tones were merged. Then the patterns were interpreted in terms of F0 movements (rising, plateau or falling) depending on whether the difference in the F0 values was larger than 3 semi-tones or not [34].

This led to a set of 15 patterns that are later denoted according to the F0 movements, and to the F0 level on the discourse markers. For example, ' $r$ H_p' indicate a high F0 level on the word in question, rising from the left context, and plateau toward the right context. F0 values for frequently used patterns are reported in Table 3. In the examples reported, the notations for the slopes are ' $r r$ ' when rising more than 6 semi-tones, ' $r$ ' when rising more than 3 semi-tones, 'p' when it is a plateau and ' $\mathrm{f}$ ' when falling. The F0 level on the words in question is denoted ' $\mathrm{H}$ ' for high (more than 3 semi-tones above median value), 'Mh' for medium-high ( about 1 semi-tone above median value), ' $M$ ' for median value, and ' $L$ ' for low, (lower than 3 semi-tones beneath median value).

Table 3: F0 values (compared to speaker's median F0 value) for frequently obtained F0 patterns

\begin{tabular}{|c|c|c|c|c|}
\hline & No. of items & F0 on w-1 & F0 on w & F0 on w+1 \\
\hline rr-H-p & 63 & -1.2 & 7.2 & 5.3 \\
\hline r-H-f & 135 & -0.8 & 3.6 & 0.6 \\
\hline p-Mh-p & 137 & 1.7 & 1.2 & 3.7 \\
\hline f-M-p & 215 & 3.6 & 0.1 & 0.1 \\
\hline r-M-p & 133 & -4.9 & -0.4 & -0.5 \\
\hline p-M-p & 388 & -0.3 & -0.5 & -0.3 \\
\hline p-M-rr & 69 & -1.6 & -0.8 & 8.7 \\
\hline p-L-r & 136 & -2.5 & -4.0 & 0.9 \\
\hline
\end{tabular}

\section{Impact of speaking style}

The first set of comparisons concerns the behaviour of the prosodic parameters according to the speaking style, that is spontaneous speech vs. prepared speech in French.

\subsection{Pauses before and/or after discourse markers}

The presence of pauses immediately before and after the words under study is detailed in Table 2 . The table shows the number of occurrences of the words used as a non-marker, and then those of each pragmatic function when used as a discourse marker. Regarding the presence of pauses, there are four possible contexts: no pause (neither before nor after), a pause before only, a pause after only, and a pause before and after.

The first observation we can draw from the table is the difference of pause occurrences between the usage of the word as non-DM (i.e., with its original lexical meaning) and the usage of the word as a discourse marker. Non-DM are most frequently accompanied by an absence of pause, both before and after the word.

When the words are used as discourse markers, for most of the cases, there are frequent occurrences of pauses, mainly before the discourse marker, and to a smaller extent before and after the discourse marker. Overall, pause occurrences are quite similar between spontaneous speech and prepared speech for the discourse markers 'alors' and 'bon'. 'bon' was never used to introduce a conclusion in prepared speech, whereas it was used for that in spontaneous speech with a pause before, and also after it. However, significant differences are observed for the discourse marker 'donc'. For the pragmatic function 'Introduction', 'donc' is almost always produced without a pause in prepared speech, whereas a pause before is the prevalent case in spontaneous speech. We observe a somewhat similar behaviour for the pragmatic functions 'Conclusion' and 'Parenthesis', but the difference in the presence of pauses before, between prepared and spontaneous speech, is much smaller. 
Table 4: Number of occurrences of discourse markers and percentage of most frequent patterns

\begin{tabular}{|c|c|c|c|c|c|c|c|c|c|c|c|c|}
\hline & & NoItems & rr_H_p & r_H_f & p_Mh_p & f_M_p & r_M_p & P_M_p & f_M_p & M_rr & p_MI_p & p_L_r \\
\hline \multirow{3}{*}{$\begin{array}{l}\text { None } \\
\text { (Non-DM usage) }\end{array}$} & French-Spontaneous & 181 & $2 \%$ & $13 \%$ & $8 \%$ & $10 \%$ & $6 \%$ & $25 \%$ & $3 \%$ & $4 \%$ & $7 \%$ & $6 \%$ \\
\hline & French-Prepared & 92 & $10 \%$ & $11 \%$ & $5 \%$ & $16 \%$ & $4 \%$ & $11 \%$ & & $7 \%$ & $4 \%$ & $4 \%$ \\
\hline & English-Prepared & 147 & $7 \%$ & $10 \%$ & $12 \%$ & $7 \%$ & $3 \%$ & $19 \%$ & $5 \%$ & $1 \%$ & $7 \%$ & $5 \%$ \\
\hline \multirow{3}{*}{ Introduction } & French-Spontaneous & 28 & & $11 \%$ & $11 \%$ & $14 \%$ & $7 \%$ & $25 \%$ & & & $7 \%$ & $11 \%$ \\
\hline & French-Prepared & 25 & $4 \%$ & $12 \%$ & $4 \%$ & $16 \%$ & $4 \%$ & $24 \%$ & $12 \%$ & $4 \%$ & $4 \%$ & $4 \%$ \\
\hline & English-Prepared & 7 & $14 \%$ & $29 \%$ & $14 \%$ & & & $14 \%$ & & $14 \%$ & & $14 \%$ \\
\hline \multirow{3}{*}{ Conclusion } & French-Spontaneous & 88 & & $3 \%$ & $3 \%$ & $14 \%$ & $9 \%$ & $24 \%$ & $2 \%$ & $1 \%$ & $15 \%$ & $12 \%$ \\
\hline & French-Prepared & 22 & $5 \%$ & $9 \%$ & $5 \%$ & $23 \%$ & & $18 \%$ & & $5 \%$ & $14 \%$ & $9 \%$ \\
\hline & English-Prepared & 12 & $8 \%$ & & $25 \%$ & & $25 \%$ & $42 \%$ & & & & \\
\hline \multirow{3}{*}{ Parenthesis } & French-Spontaneous & 193 & $1 \%$ & $5 \%$ & $3 \%$ & $19 \%$ & $11 \%$ & $25 \%$ & $8 \%$ & $3 \%$ & $7 \%$ & $7 \%$ \\
\hline & French-Prepared & 70 & $1 \%$ & $10 \%$ & $6 \%$ & $24 \%$ & $6 \%$ & $11 \%$ & $6 \%$ & $3 \%$ & $7 \%$ & $9 \%$ \\
\hline & English-Prepared & 22 & $5 \%$ & $5 \%$ & $18 \%$ & $9 \%$ & $18 \%$ & $9 \%$ & $5 \%$ & $18 \%$ & & $9 \%$ \\
\hline
\end{tabular}

\subsection{F0 articulation with left and right contexts}

Table 4 reports the frequency of the most frequently observed F0 patterns on French spontaneous and French prepared speech and English prepared speech, when there is no pause, neither before, nor after the word. The F0 values of the patterns are reported in Table 3 .

'Falling-median-plateau', 'rising-median-plateau' and 'plateau-median' are frequent patterns for French words when not used as discourse markers, and even more frequent in spontaneous speech.

For the French language, and for the pragmatic function 'Introduction', the frequency of the F0 patterns is similar in spontaneous speech and prepared speech. This is almost the same for 'Conclusion' if we accumulate the frequencies of occurrences of the 'falling-median-plateau' and 'rising-median-plateau' patterns. For 'Parenthesis', the 'plateau-median-plateau' pattern is more frequently used in spontaneous speech.

Due to lack of space, we will not report results on patterns observed when there is a pause before, and when only the F0 articulation with to the right context is considered.

\section{Comparison between the two languages}

In this section, we compare the prosodic characteristics of our discourse markers in French in English.

\subsection{Pauses before and/or after discourse markers}

Table 2 shows no significant differences between the English and the French words when the words are not used as discourse markers. In this case, most of the time, there is no pause, neither before, nor after the words under consideration.

When the English words are used as discourse markers, the presence of a pause before becomes the dominant pattern for all the pragmatic functions considered. And in a significant number of cases there is also a pause after the discourse markers. Overall the pause occurrences for the three English discourse markers are rather similar to what is observed for the French discourse markers 'alors' and 'bon'.

The frequent presence of pauses around the discourse markers studied in both languages shows their relative syntactic independence highlighted by prosodic means. Indeed, when the semantic load of these words is maintained, they are more prosodically anchored, occurring in non-separated intonation groups whereas they frequently occur in independent intonation groups when used as discourse markers.

\subsection{F0 movements with respect to immediate context}

Comparison between F0 patterns in French and English prepared speech is reported in the last two columns of Table 4.

When the word is not used as a discourse marker, median F0 level is frequently observed in both languages.

When a discourse marker has the pragmatic function 'Introduction', the pattern 'rising-High-falling' is very frequent in English, whereas it is less frequent in French. For 'Conclusion' and 'Parenthesis', the 'plateau-median-high-plateau' pattern is almost never used in French data, but frequently used in English. A similar case is observed for the "plateau-Median-risingrising' pattern for the pragmatic function 'Parenthesis'.

\section{Conclusions}

In this paper, we have analysed the prosodic characteristics of 6 words frequently used as discourse particles in French and in English. Prosodic characteristics are compared between two speaking styles, spontaneous speech vs. prepared speech, on the French data. Moreover, on prepared speech, prosodic characteristics are compared between French and English discourse markers. We have focused our analysis on the presence of pauses before and/or after the words under consideration, and on the F0 patterns and their articulation with the immediate, left and right contexts. The analysis has been carried out on several hundred of occurrences that have been randomly extracted from large speech corpora.

With respect to the presence of pauses around the words, the analysis shows significant differences between words keeping their lexical meaning (i.e. not discourse markers) with very few occurrences of pauses observed, and words used as discourse markers where pauses are frequently observed before and also sometimes after the words. This is true in both speaking styles and in both languages. Some differences in pause occurrences are observed between spontaneous speech and prepared speech, but differences are smaller in prepared speech across the two languages

F0 patterns with respect to immediate left and right contexts have also been analysed and compared between speaking styles and languages. The usage of some patterns appears to be language specific, although many patterns are frequently used in both languages.

\section{Acknowledgements}

This work has been partially supported by the CPER LCHN (Contrat Plan État Région "Langues, Connaissances et Humanités Numériques"). 


\section{References}

[1] M. B. M. Hansen, "The function of discourse particles: A study with special reference to spoken standard French", vol. 53. John Benjamins Publishing, 1998.

[2] D. Schiffrin, "Discourse markers", n. 5, Cambridge University Press, 1987

[3] K. Aijmer, "English discourse particles: Evidence from a corpus", vol. 10, John Benjamins Publishing, 2002.

[4] J. Hirschberg and D. Litman, "Empirical studies on the disambiguation of cue phrases", Computational linguistics, vol. 19, $\mathrm{n}^{\circ} 3$, pp. 501-530, 1993.

[5] M. J. Cuenca, "Pragmatic markers in contrast: The case of well". Journal of Pragmatics, vol. 40, $\mathrm{n}^{\circ}$ 8, pp. 1373-1391, 2008.

[6] C. Chanet, "1700 occurrences de la particule quoi en français parlé contemporain: approche de la «distribution» et des fonctions en discours", Marges linguistiques, vol. 2, pp. 56-80, 2001.

[7] K. Aijmer and A. M. Simon-Vandenbergen, "Pragmatic markers", Discursive pragmatics, vol 8, pp. 223-247, 2011.

[8] C. Y. Tseng, "Higher level organization and discourse prosody". Proceedings of Tonal Aspects of Languages, La Rochelle, France, pp. 7-18, 2006.

[9] E. Liebenthal, D. A. Silbersweig and E. Stern, "The language, tone and prosody of emotions: neural substrates and dynamics of spoken-word emotion perception", Frontiers in neuroscience, vol. 10, p. 506, 2016.

[10] D. A. Sauter, F. Eisner, A. J. Calder and S. K. Scott, "Perceptual cues in nonverbal vocal expressions of emotion", The quarterly journal of experimental psychology, vol. 63, $\mathrm{n}^{\circ} 11$, pp. 22512272, 2010.

[11] M. Horne, P. Hansson, G. Bruce, J. Frid and M. Filipsson, "Discourse markers and the segmentation of spontaneous speech-The case of Swedish men 'but/and/so"'. Lund Working Papers in Linguistics, vol. 47, pp. 123-139, 2009.

[12] A. Wichmann, "Prosody and discourse: a diachronic approach", Proceedings Conference Interfaces Discours Prosodie (IDP), Aix en Provence, France, pp. 1-11, 2005.

[13] V. Cabarrão, H. Moniz, J. Ferreira, F. Batista, I. Trancoso, A. I Mata and S. Curto, "Prosodic classification of discourse markers", Proceedings ICPhS 2015, International Congress of Phonetic Sciences. International Phonetic Association, Glasgo, UK, 2015.

[14] L. J. Brinton, The evolution of pragmatic markers in English: Pathways of change, Cambridge University Press, 2017.

[15] A. Wichmann, A. M. Simon-Vandenbergen and K. Aijmer, "How prosody reflects semantic change: A synchronic case study of of course", Subjectification, intersubjectification and grammaticalization, pp. 103-154, 2010

[16] A. Gravano, Š. Beňuš, H. Chávez, J. Hirschberg and L. Wilcox, "On the role of context and prosody in the interpretation of 'okay", Proceedings ACL 2007, 45th Annual Meeting of the Association of Computational Linguistics, Prague, Czech Republic, pp. 800-807, 2007.

[17] S. Benus, A. Gravano and J. B. Hirschberg, "Prosody, emotions, and...'whatever'", Proceedings INTERSPEECH 2007, 8th Annual Conference of the International Speech Communication Association, Antwerp, Belgium, 2007.

[18] M. Dargnat, K. Bartkova and D. Jouvet, "Discourse particles in French: prosodic parameters extraction and analysis", Proceedings SLSP 2015, International Conference on Statistical Language and Speech Processing, Budapest, Hungary, pp. 39-49, 2015.

[19] K. Bartkova, A. Bastien and M. Dargnat, "How to be a Discourse Particle?", Proceedings SP 2016, Speech Prosody, Boston, USA, 2016.

[20] D. Jouvet, K. Bartkova, M. Dargnat and L. Lee, "Analysis and automatic classification of some discourse particles on a large set of French spoken corpora", Proceedings SLSP 2017, International Conference on Statistical Language and Speech Processing, Le Mans, France, pp. 32-43, 2017.

[21] L. Lee, K. Bartkova, D. Jouvet, M. Dargnat and Y. Keromnes, «Can prosody meet pragmatics? Case of discourse particles in
French", Proceedings ICPhS 2019, International Congress on Phonetic Sciences, Melbourne, Australie, 2019.

[22] J. M. Debaisieux, C. Benzitoun and H. J. Deulofeu, « Le projet ORFEO : Un corpus d'études pour le français contemporain ", Revue Corpus, Corpus de français parlé et français parlé des corpus, vol. 15, pp.91-114, 2016

[23] S. Galliano, G. Gravier and L. Chaubard, "The ESTER 2 evaluation campaign for the rich transcription of French radio broadcasts", Proceedings, INTERSPEECH 2009, Tenth Annual Conference of the International Speech Communication Association, Brighton, UK, 2009

[24] F. Hernandez, V. Nguyen, S. Ghannay, N. Tomashenko and Y. Estève, "TED-LIUM 3: twice as much data and corpus repartition for experiments on speaker adaptation", Proceedings SPECOM 2018, International Conference on Speech and Computer, Leipzig, Germany, pp. 198-208, 2018

[25] Y. Maschler and D. Schiffrin, "Discourse markers: Language, meaning, and context", The handbook of discourse analysis, vol. 1, pp. 189-221, 2015.

[26] K. Beeching, "La co-variation des marqueurs discursifs bon, c'est-à-dire, enfin, hein, quand même, quoi et si vous voulez: une question d'identité ?". Langue française, vol. 2, pp. 78-93, 2007.

[27] L. Degand and B. Fagard, "Alors between discourse and grammar: the role of syntactic position", Functions of language, vol. $18, \mathrm{n}^{\circ}$ 1, pp. 29-56, 2011

[28] E. Denturck, "Étude des marqueurs discursifs. L'exemple de quoi », Faculteit Taal-en Letterkunde, Sectie 2 talen, Academiejaar 2007-2008, 2008

[29] F. Lefeuvre, "Bon et quoi à l'oral : marqueurs d'ouverture et de fermeture d'unités syntaxiques à l'oral", Linx. Revue des linguistes de l'université Paris X Nanterre, vol. 64-65, pp. 223-240, 2011 .

[30] D. Talkin, "A robust algorithm for pitch tracking (RAPT)", In Speech Coding and Synthesis, W. B. Kleijn and K. K. Paliwal, Eds. Elsevier, pp. 495-518, 1995.

[31] SPTK: http://sp-tk.sourceforge.net/.

[32] D. Jouvet and Y. Laprie, "Performance Analysis of Several Pitch Detection Algorithms on Simulated and Real Noisy Speech Data”, Proceedings EUSIPCO 2017, 25th European Signal Processing Conference, Kos, Greece, 2017.

[33] C. De Looze and D. Hirst, "L'échelle OME (Octave-MEdiane) : une échelle naturelle pour la mélodie de la parole", Proceedings JEP 2010, XXVIIIème Journées d'Étude sur la Parole, Mons, Belgium, 2010.

[34] P. Mertens and C. d'Alessandro, « Pitch contour stylization using a tonal perception model", Proceedings ICPhS 1995, 13th International Congress of Phonetic Sciences, vol. 4, pp. 228-231, 1995. 